suggests that American medicine is as uncertain as Britain appears to be about the function of the "generalist" in the day-to-day care of the sick and injured. In attempting to solve a highly complex problem in the context of modern medicine, we don't think that the formation of still another association will be of much help. In fact, however worthy the aims of the new association may appear to be, it will end by diluting effort when effort needs to be concentrated, and by blurring responsibility at a time when it needs bringing into sharper focus.

The British Medical Association, if only because of its size, is an easy target for the discontented. Like any other human institution it can make mistakes, and its critics have eyes wide open for its mistakes and are wilfully blind to its considerable and continuing achievements. But when it comes to the question of the payment of general practitioners in the Health Service, those who are now expressing their dissatisfaction should remember that for some 50 years general practitioners have themselves been directly responsible for negotiating their terms and conditions of service with the Ministry of Health, first of all under National Health Insurance, and since 1948 under the National Health Service. So satisfied were general practitioners with the machinery under National Health Insurance that they adopted it without hesitation with the coming into force of the N.H.S. in July, 1948.

The General Medical Services Committee is largely composed of doctors elected by representatives of local medical committees, and membership is open to any G.P. in the Health Service, whether he is or is not a member of the B.M.A. Although technically speaking the G.M.S.C. is a B.M.A. committee, it is, paradoxically enough, possible for its chairman to be someone who is not, and may never have been, a member of the B.M.A. The G.M.S.C. is an autonomous body within the framework of the B.M.A., and it has its own considerable fighting funds, to which most G.P.s in the N.H.S. contribute. It therefore seems to us a great pity, to say the least of it, that an attempt should now be made to form another fund separate from this. The G.M.S.C.'s funds are, it should be stressed, completely under the control of the general practitioners in the National Health Service, and completely outside the control of the British Medical Association.

Dr. Biss and his colleagues should tread the wellworn democratic path by getting themselves and their sympathizers elected as representatives to the Conference of Representatives of Local Medical Committees, and from there to the central G.M.S.C. We suggest, too, that whatever justice there may be in some of the criticisms now made about remuneration and methods of remuneration, the critics are being less than fair to their own appointed representatives of general practitioners in the N.H.S. It is, after all, not so long ago that the General Medical Services Committee secured for their colleagues in the Health Service the enormous increase in money that came to them through the Danckwerts Award in 1952. It is necessary, too, to point out that the general practitioners, with other sections of the profession, agreed to the setting-up of the Review Body and to the method of working out on a long-term basis the remuneration of doctors in the Health Service. Owing to the labyrinth-like nature of the present method of paying doctors on the basis of the pool plus capitation fees, the recent Review Body award has not put into general practitioners' pockets the money they thought they were going to get this year. This is the fault neither of the B.M.A., nor of the R.B., nor of the G.M.S.C., nor of the Ministry of Health, nor even of the Review Body-it is because of the unsatisfactory nature of the pool and capitation method of payment. It is a method that has not been without benefit in the past, but it is probably time it was changed. And the Representative Body has already decided that this should be done.

We would therefore appeal to those who are dissatisfied, and who are expressing it in current ways, to think twice about joining still another association and leaving at a difficult moment in its history the one body which has faithfully negotiated with governmental and other bodies in the interests of the profession as a whole, and will continue to do so. The B.M.A. needs the constructive advice and action of its members in the hard task it has immediately in front of it in resolving so many of the real difficulties facing those practising medicine in Britain to-day, and not least general practitioners. Some of these difficulties were referred to in a recent leading article, ${ }^{2}$ and are commented on in the letter from Dr. J. G. M. Hamilton in this week's correspondence columns (p. 994).

\section{CHILDREN IN HOSPITAL}

Opinions in the profession on how children should be accommodated in hospital have varied from time to time and from one country to another. To-day, with funds available for the building of new hospitals in this country, it is desirable to try to crystallize our views and to translate them into plans for wards and out-patient departments. The Division for Architectural Studies of the Nuffield Foundation, led by Professor R. Llewelyn Davies, undertook this task in 1956 at the suggestion of the late Sir James Spence, and the Foundation has now published its findings. ${ }^{1}$ They are of great interest and 
considerable value to all those concerned with the care of children in hospital.

A historical review forms an interesting and instructive introduction to the report. We are reminded that in 1852 the Hospital for Sick Children was opened in Great Ormond Street, and that, although other children's hospitals were soon established, children's wards became common in general hospitals and the practice of admitting children to adult wards continued. The Division was interested mainly in the services provided for children in general hospitals and "the research work was centred on general hospitals rather than on separate children's hospitals because it was evident in 1956 that the national policy was towards concentrating staff and equipment in general hospitals each providing a comprehensive service to a surrounding community." Some of the conclusions drawn from this work may therefore not be applicable to the hospital services for children as a whole or, in particular, to children's hospitals, though the final suggestions for the design of a children's ward should prove to be generally acceptable. In fact some of the studies were conducted in wards in children's hospitals. This enhances the value of the report, especially in view of recent statements by responsible officials of the Ministry of Health. They have made it clear that there is now no intention that the development of paediatric units in district general hospitals should affect existing established children's hospitals large enough to be economically acceptable and clinically efficient; and that such a hospital is indeed envisaged for every major centre of population.

An attempt was made to estimate the total number of children for whom hospital accommodation is likely to be required in the future and to answer the questions: How many beds for children will be needed, immediately and in the foreseeable future, and for what clinical specialties will they be required? Official figures suggest a continuing future increase in the total number of children in this country. Some information on the existing demand for and apparent trends in the hospital care of children has been given, ${ }^{23}$ but the Division recognizes that they do not give a representative overall picture of the demand for hospital care for children in this country. Considerable regional differences exist in the numbers and clinical kinds of hospital beds needed for children, and the Division concludes that an ad hoc case-load study is necessary to establish the particular needs of any community for whom major

\footnotetext{
Children in Hospltal. Ed. by Barbara M. Duncum, D.Phil. London : Oxford
University Press, 1963. 2 Ministry of Health and General Register Office. Report on Hospital In-patient
Enquiry for the Years 1956-57. 1961. H.M.S.O.

Illingworth, R. S., and Knowelden, J., Lancet, 1961, 1, 877.

- Mackay, D., Hospttal Morbidity Statistics: A preliminary study of in-patient

- Welfare of Children in Hospital. H.M.S.O. 1959.
}

alterations in the provision of hospital beds are in prospect. This is clearly sound policy and it is to be hoped that it will be regularly applied in future.

The Division also emphasizes that to be able to plan sufficiently far ahead, where children are concerned, more will have to be discovered about the pace and trends in the hospital care of children. An attempt to define some of these trends from a study of recent surveys and diagnostic analyses of the Ministry in the two years $1949^{4}$ and $1957^{2}$ showed that the most notable increase in relative importance was in the diagnostic class "all diseases of infancy" (excluding feeding problems) from $3 \%$ in 1949 to $8 \%$ in 1957-a trend which continues to-day and necessitates more cots in most children's units. Acute infection of the lower respiratory tract was one of the commonest reasons for admitting babies. If the hospital services are to be able to cope adequately with epidemics of such infection when they occur the authorities must accept as inevitable at other times some empty cots in children's wards and their adverse effect on statistics of bedoccupancy. Congenital abnormalities ranked second only to tonsillectomy as a cause of admission. This underlines the need for an adequate number of paediatric surgeons and for the extension of the neonatal surgical services. The Division endorsed particularly the recommendation of the Platt Committee ${ }^{5}$ and the Ministry's present policy that in general hospitals children should be nursed in children's departments and not in wards for adults and that those departments should be of at least 40 beds.

Children over 12 years old were studied separately, and it was considered that where there are enough cases small wards for adolescents are highly desirable. For children needing prolonged treatment in hospital small wards of fourteen to sixteen beds attached to the larger children's departments were favoured. A review of the needs of such children in a region with a large, dense urban population would probably have shown the necessity for many more beds for the region as a whole and might have pointed to the advantages, physical and educational, of a large, long-stay hospital in the country, in spite of the statement in the foreword to the Report that "hospitals for long-stay cases are obsolescent."

A study of nursing in children's wards was limited to general hospitals in the Oxford Region. Hospitals visited were found to be short of nurses of all grades. That this shortage exists throughout the country and is most noticeable in the few children's hospitals which are not contributing to the training of the Registered Sick Children's Nurse Certificate and in the children's departments of general hospitals was shown by a review 
of the nursing services for children conducted in 1962 by the British Paediatric Association. Yet the present policy of the General Nursing Council is to abolish this certificate. It is to be hoped that the Council will pay heed to the recommendation of the British Paediatric Association that, in order to attain a very necessary increase in the number of nurses training for and trained in sick children's nursing and to maintain the necessary standards, the three-year course for the Registered Sick Children's Nurse Certificate should be retained ; for no aspect of the care of children in hospital is of greater importance than the future of the nursing services.

All this information on all aspects of the care of the child in hospital produced pointers to the design for a ward for twenty children and up to four mothers, and the Division's suggestions and plans have much to commend them. They will undoubtedly be of great assistance to those concerned with hospital accommodation for children in the future.

In a final brief chapter of the report a survey is made of the out-patient services for children in two similar hospital groups, one in the Oxford and the other in the East Anglian Region. The provision of a children's out-patient department separate from the general outpatient department as recommended by the Platt Committee $^{4}$ was thought to be "unrealistic." While this may have been a reasonable deduction for these hospital groups, similar studies in other groups and other regions would certainly have lent support to the Platt Committee's recommendation and would have revealed its especial importance in relation to accident services.

\section{INSOMNIA IN DEPRESSION}

Though E. Mapother ${ }^{1}$ attacked the traditional view that depression could not be subdivided and so set in train the controversies of the 1930 's, psychiatrists still usually classify depression into endogenous and neurotic. Characteristics of endogenous depression are often the cyclothymic personality and pyknic build of the patient, early waking, diurnal variation of mood, mental retardation, reduction in appetite and libido, a positive family history, and a liability to recurrence. Neurotic depression is apt to occur in an immature personality in response to stress; self-pity is evident, the depression is worse in the evening than at other times, and insomnia is in the earlier part of the night. On this traditional view one important point of differentiation between these types of depression is that, though insomnia occurs in both, the patterns are different.

J. M. Hinton ${ }^{2}$ recently studied the sleep patterns of 34 patients, 27 with endogenous depression and 7 with reactive depression. His patients were kept under observation throughout the night by a nurse, and motility of the patient throughout the night was also recorded. He showed

1 Mapother, B., Brit. med. J.. 1926, 2, 872.

2 Hinton, J. M., J. Neurol. Neurosurg. Psychiat., 1963, 26, 184

3 Kiloh, L. G., and Garside, R. F., Brit. J. Psychiat., 1963, 109, 451. on both criteria that depressed patients certainly sleep less than depressives who have recovered. There was, however, no difference between those who had been diagnosed as endogenous and those who had been diagnosed as reactive depressives, and neither group suffered greater loss of sleep in the second half of the night than in the first. $\mathrm{He}$ does not say what criteria his colleagues used in making the original diagnoses of endogenous or reactive depression but presumably insomnia was not one of them. An extensive review by L. G. Kiloh and R. F. Garside ${ }^{3}$ is relevant to these problems. They analysed the symptoms of 143 depressed patients. In 92 cases they were confident of their diagnoses; 61 were reactive and 31 endogenous. In the remaining 51 cases the diagnoses were doubtful. Thirty-five clinical features were selected for statistical analysis. Their data show that there must be two separate depressive conditions. This is perhaps not entirely surprising, as they were analysing the data from patients of whom two-thirds had already been selected as clearly falling into one of two groups on the basis of the features being analysed. However, apart from this bias, what is of present relevance is that there was one group of patients with a preponderance of the features of endogenous depression and another with those of reactive depression; the former showed early waking and the latter initial insomnia.

From the practical point of view these authors agree on one important point-that depressed patients do suffer from insomnia. Most psychiatrists will continue to think that patients with endogenous depression have early waking, while those with reactive depression suffer from initial insomnia. The depressed patient finds insomnia one of his most unpleasant symptoms. It prolongs the amount of waking time that he is in misery, and the endogenously depressed patient is awake in the small hours when he is most depressed. It is important that this insomnia be effectively treated by means of hypnotics. Fortunately, again from the practical point of view, it does not matter whether the patient suffers from initial insomnia or early waking, because he can be given the same barbiturates in both cases. As was said recently in these columns, ${ }^{4}$ there appears to be little merit in varying the barbiturate according to the time at which the patient is wakeful. What matters is that the patient should have an effective dose. If he is being treated as an out-patient, the hypnotics should be given into the care of a responsible relative.

\section{BEETURIA}

For many years the term anthocyanuria has been used to describe the occasional finding of a red pigment in the urine after eating beetroot. This name is incorrect, since the pigment derived from beet is betanin, which is not an anthocyanin, and the condition should be called beeturia. It has usually been emphasized that beeturia is harmless, its importance being solely in differential diagnosis -for example, from haemoglobinuria. The pigment is readily recognized by the change in colour of the urine from red to yellow on the addition of alkali and by the return to red on reacidification. It also has a characteristic spectrum.

\footnotetext{
1 Allison, A. C., and McWhirter, K. G., Nature (Lond.), 1956, 178, 748.
2 Zindler, G. A., and Colovos, G. C., Ann. Allergy, 1950, 8, 603.
} 